\title{
Discovery of BMS-641988, a Novel Androgen Receptor Antagonist for the Treatment of Prostate Cancer
}

\author{
Aaron Balog, ${ }^{*}{ }^{\dagger}$ Richard Rampulla, ${ }^{\dagger}$ Gregory S. Martin, ${ }^{\ddagger}$ Stanley R. Krystek, ${ }^{\dagger}$ Ricardo Attar, ${ }^{\dagger}$ \\ Janet Dell-John, ${ }_{\dagger}^{\dagger}$ John D. DiMarco, ${ }^{\dagger}$ David Fairfax, ${ }^{\dagger}$ Jack Gougoutas, ${ }^{\dagger}$ Christian L. Holst, ${ }^{\dagger}$ \\ Andrew Nation, ${ }^{\dagger}$ Cheryl Rizzo, ${ }^{\dagger}$ Lana M. Rossiter, ${ }^{\dagger}$ Liang Schweizer, ${ }^{\dagger}$ Weifang Shan, ${ }^{\dagger}$ Steven Spergel, ${ }^{\dagger}$ \\ Thomas Spires, $^{\dagger}$ Georgia Cornelius, ${ }^{\dagger}$ Marco Gottardis, ${ }^{\dagger}$ George Trainor, ${ }^{\dagger}$ Gregory D. Vite, ${ }^{\dagger}$ \\ and Mark E. Salvati ${ }^{\dagger}$
}

${ }^{\dagger}$ Bristol Myers-Squibb Research and Development, Princeton, New Jersey 08543, United States

${ }^{\ddagger}$ Albany Molecular Research Inc., 21 Corporate Circle, Albany, New York 12203, United States

Supporting Information

\begin{abstract}
BMS-641988 (23) is a novel, nonsteroidal androgen receptor antagonist designed for the treatment of prostate cancer. The compound has high binding affinity for the $\mathrm{AR}$ and acts as a functional antagonist in vitro. BMS641988 is efficacious in multiple human prostate cancer xenograft models, including CWR22-BMSLD1 where it displays superior efficacy relative to bicalutamide. Based on its promising preclinical profile, BMS-641988 was selected for clinical development.
\end{abstract}

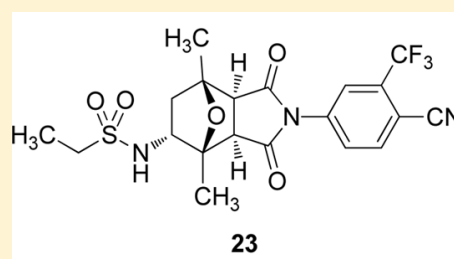

MDA-MB-453 Ki = $1.7 \mathrm{nM}$

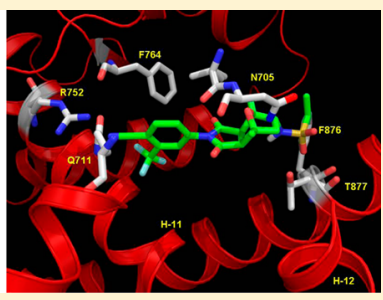

KEYWORDS: Prostate cancer, androgen receptor, CRPC, BMS-641988

$\mathrm{C}$ arcinoma of the prostate $(\mathrm{CaP})$ is the most common malignancy among men in the US and the second most common cause of cancer-related death worldwide after lung cancer. ${ }^{1}$ The androgen receptor (AR) is a member of the nuclear hormone superfamily of ligand-induced transcription factors and is a key signaling pathway leading to the emergence of $\mathrm{CaP}$. Androgen ablation, by surgical or chemical castration in combination with an antiandrogen such as hydroxyflutamide (1) or bicalutamide (2), has been the standard of care for advanced $\mathrm{CaP}$ for many years. ${ }^{2}$ This therapy is initially effective in $80-90 \%$ of patients; however, $>50 \%$ of the patients will ultimately develop castration resistant prostate cancer (CRPC) after $\sim 18$ months. ${ }^{3}$ The treatment of CRPC is challenging due to the sustained AR signaling, which is the result of $A R$ overexpression/activation and the presence of activating $A R$ mutations. ${ }^{4}$ Furthermore, it has been reported that CRPC tumors express the necessary cytochrome P450 enzymes for intratumoral androgen production, thus bypassing the effects of chemical castration, which targets only gonadal androgen production. ${ }^{5}$ These findings suggest that CRPC remains AR dependent, and effective therapies must target AR signaling directly with improved next-generation AR antagonists.

MDV3100 (enzalutamide, 3 ) is a potent AR antagonist that was recently approved by the US Food and Drug Administration for the treatment of metastatic CRPC patients that have progressed post-treatment with docetaxel. ${ }^{6}$ Although enzalutamide has shown promise in treating these patients, nearly all patients go on to develop resistance to enzalutamide via AR mutations. ${ }^{4}$ Thus, there is a need for novel antiandrogens with distinct interactions in the AR ligand binding domain that could be dosed together or sequentially in the clinic to combat the potential pathways leading to CRPC progression. Our laboratory has been focused on the rational structural-based design of structurally novel, nonsteroidal small molecule AR antagonists for the potential treatment of CRPC.

Previously, we have reported a series of [2.2.1] carbobicyclic $^{7}$ and oxabicyclic ${ }^{8}$ succinimide based AR antagonists (4 and 5, Figure 1). These compounds demonstrated potent binding affinity $\left(K_{\mathrm{i}}\right)$ and functional antagonist activity $\left(\mathrm{IC}_{50}\right)$ against the wild-type AR as found in the MDA-MB-453 cell-line (Table 1). These compounds compared favorably in terms of potency to the clinically used antiandrogens hydroxyflutamide (1) and bicalutamide (2). We designed a series of oxabicyclic-based AR

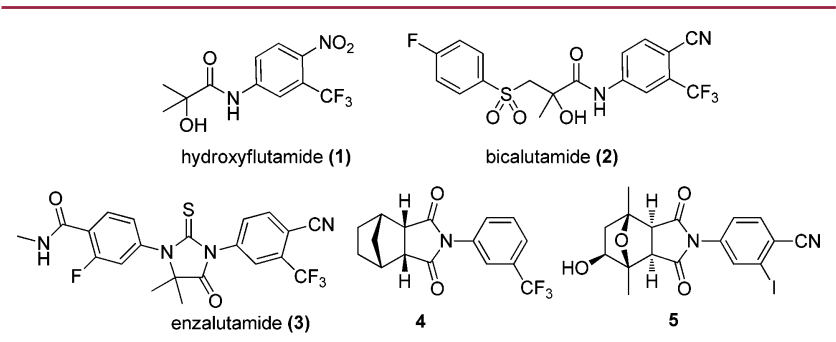

Figure 1. Known androgen receptor antagonists.

Received: April 24, 2015

Accepted: June 19, 2015

Published: June 19, 2015 
Table 1. In Vitro Biological Activity

\begin{tabular}{|c|c|c|}
\hline$\#$ & MDA-MB-453 $K_{\mathrm{i}}(\mathrm{nM})^{a}$ & MDA-MB-453 $\mathrm{IC}_{50}(\mathrm{nM})^{b}$ \\
\hline 2 & 64 & 173 \\
\hline 5 & 8 & 10 \\
\hline 11 & 1600 & $>5000$ \\
\hline 12 & 23 & 22 \\
\hline 13 & 50 & 34 \\
\hline 14 & 31 & 60 \\
\hline 15 & 3.0 & 23 \\
\hline 16 & 50 & 34 \\
\hline 17 & 31 & 60 \\
\hline 18 & 7.0 & 6 \\
\hline 19 & 12 & 20 \\
\hline 20 & 10 & 1.0 \\
\hline 21 & 1.0 & 10 \\
\hline 22 & 2.0 & 7.0 \\
\hline 23 & 1.7 & 16 \\
\hline
\end{tabular}

${ }^{a}$ Binding $\left(K_{\mathrm{i}}\right)$ determined through direct displacement with $\left[{ }^{3} \mathrm{H}\right]$ DHT in the MDA-MB-453 cell-line ${ }^{b}$ Functional antagonist activity $\left(\mathrm{IC}_{50}\right)$ in the MDA-MB-453 cell-line determined through a transiently transfected reporter system utilizing the secreted alkaline phosphatase reporter gene driven by the AR-dependent PSA promoter.

antagonists, such as $\mathbf{5}$, that demonstrated a superior pharmacokinetic (PK) profile compared to the carbocycles such as 4. Based on our understanding of the need for sustained AR suppression in an effective AR antagonist, we expected that robust PK would be essential for an efficacious AR antagonist. ${ }^{8}$ Accordingly, compound $\mathbf{5}$ was shown to be efficacious in the CWR22-BMSLD1 human prostate cancer xenograft model, where bicalutamide shows only limited efficacy. ${ }^{8}$ We looked to incorporate $\mathrm{PK}$ properties critical for an effective $\mathrm{AR}$ antagonist, such as $\log T_{1 / 2}$, with a broader activity profile than is seen with first generation agents such as bicalutamide. Accordingly, we screened out agents against the human $\mathrm{CaP}$ model CWR22, which has been shown to be refractory to both bicalutamide and hydroxyflutamide. Based on this result, we wanted to expand the scope of this series by using a structurebased approach to identify even more potent AR antagonists.

Utilizing available X-ray cocrystal structures of the AR generated at BMS, we developed a molecular model of the WT AR LBD (Figure 2) to aid in the identification of new AR

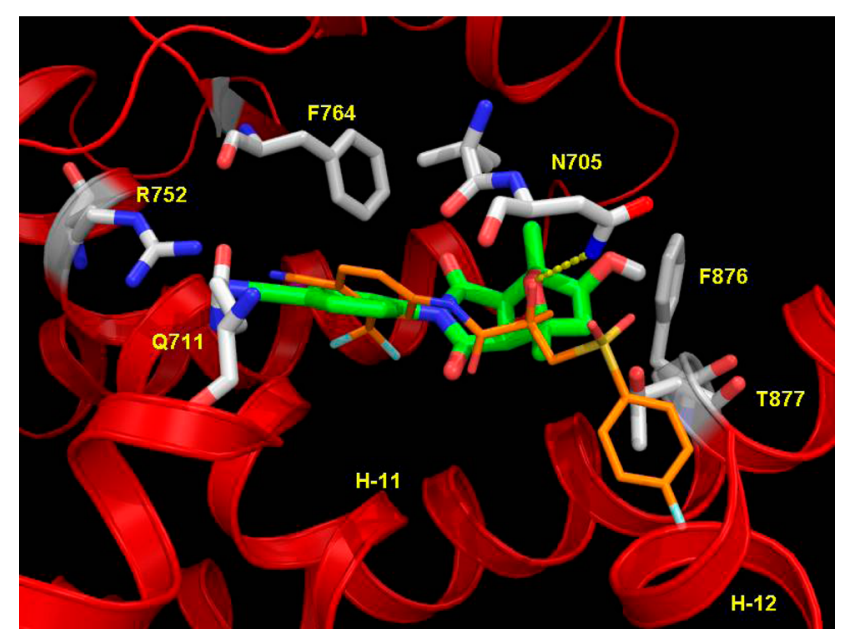

Figure 2. Compound 5 docked into a model of the wild-type AR ligand binding domain. antagonists. ${ }^{9,10}$ In this model, interactions of N-705 with both the C-5 hydroxyl and the bridging oxygen of compound 5 are evident. Additional interactions between R752 and Q711 and the aryl nitrile functionality of compound $\mathbf{5}$ are also present. We postulated that endosubstitution at C-5 or C- 6 of the bicycle would result in a direct interaction with helix-12 (H-12), possibly creating a more classical AR antagonist conformation, similar to that predicted for bicalutamide. The key hydrogen bonding interaction with $\mathrm{N}-705$ would be maintained by the bridging oxygen as seen with bicalutamide (2), which is shown in orange. Thus, we set out to investigate the effect of various substitutions on the endoface of the [2.2.1]-oxabicyclic core of compound $\mathbf{5}$.

Our efforts started with the synthesis of compounds 11-13 by the synthetic route shown in Scheme 1. Maleimide 8 was prepared from the aniline 6 and maleic anhydride (7) under standard conditions. ${ }^{11}$ Diels-Alder cycloaddition between 8 and the MEM ester of 2,5-dimethyl-3-furoic acid occurred at $120{ }^{\circ} \mathrm{C}$ to give only the desired exoisomer 9 after precipitation. Catalytic hydrogenation led to formation of the endoester by selective reduction from the beta-face of the olefin. Normalphase chiral HPLC separation of the racemic endoester gave the desired enantiomer 10 in $45 \%$ yield and $>99 \%$ ee. The optical isomer depicted by compound $\mathbf{1 0}$ was determined to be optimal for potent AR antagonist activity, and the absolute and relative stereochemistry was eventually confirmed by X-ray crystallographic analysis of compound $23 .{ }^{12}$ Treatment of $\mathbf{1 0}$ with $3 \mathrm{~N} \mathrm{HCl}$ gave the key intermediate acid 11 in good yield. Compounds 12 and 13 were prepared by standard ester and amide formation conditions.

The acid 11 was found to have poor potency in our cellular in vitro assays (Table 1), but the ester 12 and amide 13 had promising binding and functional antagonist activity in the MDA-MB-453 cell-line. Unfortunately, neither the amide nor the ester had potency that was superior to the exohydroxy analogue 5, so we investigated additional functionalities on the oxabicycle in an effort to find highly potent AR antagonists. The endoamine 14 could be prepared from the acid 11 by sequential Curtius rearrangement ${ }^{13}$ and subsequent TFApromoted cleavage of the resulting Teoc-carbamate in $77 \%$ yield. Compound $\mathbf{1 4}$ had only modest affinity to the AR but offered a good handle with which to further functionalize the oxa-bicyclic core.

A series of amides, sulfamides, carbamates, ureas, and sulfonamides was prepared from the amine 14 in library format. Standard coupling techniques were utilized to prepare analogues 15-23 (see Supporting Information); the corresponding in vitro biological data is shown in Table 1 . In general, these analogues were potent binders to, and functional antagonists of, the wild-type AR present in the MDA-MB-453 cell line. The amide $\mathbf{1 5}$ and the carbamate 18 had excellent potency in vitro, while the sulfamide 16 and urea 17 were weakly active. The sulfonamides 19-23 had the best overall in vitro profile, with robust affinity and potent antagonist activity, superior to that for bicalutamide (2).

We next wanted to investigate the pharmacodynamic effects of these novel AR antagonists in vivo. Compounds 13-23 were progressed into the immature rat prostate weight (IRPW) PK/ PD model, where the compound effect on AR-dependent growth of the prostate and seminal vesicles was measured (Table 2). ${ }^{14}$ In this model, compounds were dosed orally once a day at 1 or $10 \mathrm{mg} / \mathrm{kg}$ for 4 days with plasma concentrations of drug measured $2 \mathrm{~h}$ postdose on day 4 . Agents that effectively 
Scheme 1. Synthetic Route to Endo-Substituted Bicycles ${ }^{a}$
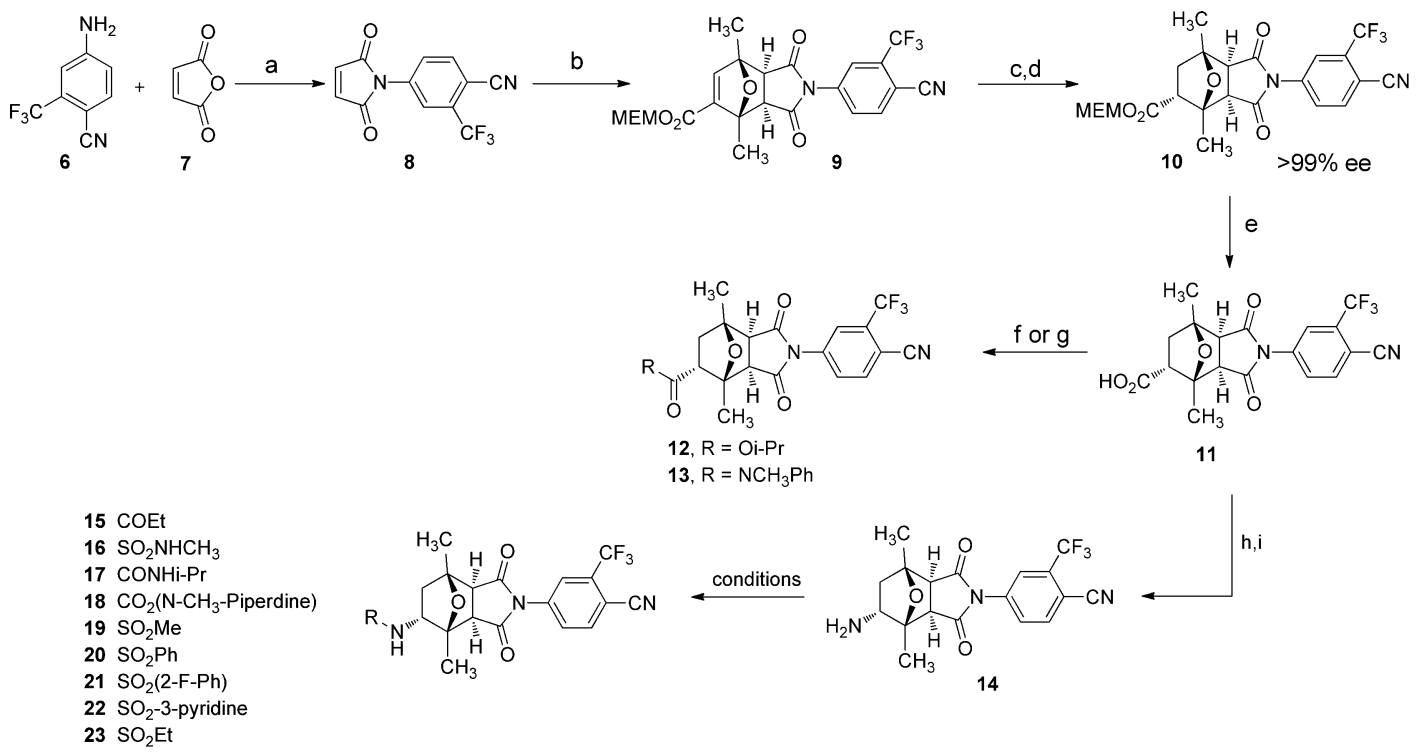

conditions

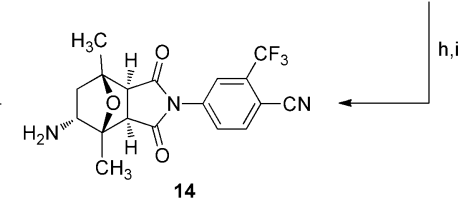

${ }^{a}$ Reagents and conditions: (a)HOAc, $110{ }^{\circ} \mathrm{C}, 88 \%$; (b) MEM 2,5-dimethyl-3-furoate, $120{ }^{\circ} \mathrm{C}, 33 \%$, exo-isomer only; (c) $\mathrm{H}_{2}, \mathrm{Pd} / \mathrm{C}, \mathrm{EtOAc}, 1 \mathrm{~atm}$, 50\%; (d) chiral HPLC separation, 45\%, >99\% ee; (e) $3 \mathrm{~N} \mathrm{HCl}$, THF, $22^{\circ} \mathrm{C}, 98 \%$; (f) $(\mathrm{COCl})_{2}$, DCM then i-PrOH, TEA, 97\%; (g) EDC, HOBt, DIEA, $\mathrm{N}$-methylaniline, DMF, 88\%; (h) 2-trimethylsilylethanol, DPPA, TEA, $4 \AA$ MS, 1,4-dioxane, $75{ }^{\circ} \mathrm{C}, 78 \%$; $(\mathrm{i}) \mathrm{TFA}^{\mathrm{C}} \mathrm{CH}_{2} \mathrm{Cl} 2,22{ }^{\circ} \mathrm{C}, 99 \%$.

Table 2. Immature Rat Prostate Weight Assay Results

$\begin{array}{lllll}\text { \# } & \begin{array}{c}\text { IRPW } \\ 1 \mathrm{mg} / \mathrm{kg} \\ \text { SV/FB }\end{array} & \begin{array}{c}\text { IRPW } \\ 10 \mathrm{mg} / \mathrm{kg} \\ \mathrm{SV}^{a} \mathrm{FB}^{a}\end{array} & \begin{array}{c}\text { exposure } \\ 1 \mathrm{mg} / \mathrm{kg} \\ (\mu \mathrm{M})^{b}\end{array} & \begin{array}{c}\text { exposure } \\ 10 \mathrm{mg} / \mathrm{kg} \\ (\mu \mathrm{M})^{b}\end{array} \\ \mathbf{2} & 69 \pm 24 & 41 \pm 4 & 2.3 \pm 0.4 & 9.5 \pm 1.4 \\ 13 & 88 \pm 19 & 43 \pm 8.0 & 1.8 \pm 0.68 & 12.0 \pm 0.82 \\ \mathbf{1 4} & 89 \pm 22 & 89 \pm 8.1 & 0.08 \pm 0.02 & 0.48 \pm 0.32 \\ \mathbf{1 5} & 87 \pm 39 & 34 \pm 6.0 & 24 \pm 1.7 & 190 \pm 73 \\ 16 & 89 \pm 5.9 & 36 \pm 4.2 & 0.01 \pm 0.001 & 0.23 \pm 0.08 \\ \mathbf{1 7} & 115 \pm 3.9 & 56 \pm 8.9 & 8.3 \pm 0.4 & 60 \pm 6.1 \\ \mathbf{1 8} & 105 \pm 24 & 87 \pm 16 & 0.012 \pm 0.004 & 0.076 \pm 0.017 \\ 19 & 64 \pm 13 & 26 \pm 4.2 & 0.29 \pm 0.07 & 4.0 \pm 1.2 \\ \mathbf{2 0} & 63 \pm 14 & 31 \pm 5.2 & 0.23 \pm 0.03 & 2.4 \pm 0.52 \\ \mathbf{2 1} & 56 \pm 6.5 & 24 \pm 1.8 & 0.16 \pm 0.02 & 1.9 \pm 0.06 \\ \mathbf{2 2} & 44 \pm 8.6 & 23 \pm 11 & 0.05 \pm 0.01 & 0.52 \pm 0.09 \\ \mathbf{2 3} & 58 \pm 13 & 26 \pm 3.0 & 0.79 \pm 0.17 & 4.0 \pm 0.42\end{array}$

${ }^{a} \mathrm{SV} / \mathrm{FB}$ is the percentage of weight of the seminal vesicles over the full body weight of the rat $(n=3)$ where testosterone treated control = $100 \%$ and sham $=10 \%$. ${ }^{b}$ Plasma exposure measured $2 \mathrm{~h}$ postdose on day 4 .

block the proliferative effect of the AR in these tissues would result in a decrease in the total weight of organs relative to a control group. As expected, the amide 13 had poor pharmacodynamic effect in this model, most likely due to modest functional antagonist potency. The amide $\mathbf{1 5}$ and the urea 17 gave only modest PD effects even with very high exposure after 1 and $10 \mathrm{mg} / \mathrm{kg}$ doses. This result correlated with the very high serum protein binding measured for these two compounds ( $>99 \%$ in mouse serum). The sulfonamide 16 and the carbamate $\mathbf{1 8}$ also had only modest PD effects, but this was most likely due to poor exposure relative to compound 2 . The sulfonamide series stood out in the IRPW model by having excellent PD with modest exposure, suggesting superior in vivo potency compared to the ureas, amides, carbamates, and sulfamides. Compounds 19-23 all demonstrated robust PD at a $10 \mathrm{mg} / \mathrm{kg}$ dose with exposures significantly less than observed for bicalutamide. Of these promising analogues, the ethyl sulfonamide $\mathbf{2 3}$ was chosen for further studies due to robust potency in vivo and a promising PK profile in rats.

Compound 23 was further profiled to determine in vitro safety and $\mathrm{ADME}$ properties (Table 3 ). Inhibition of human cytochrome $\mathrm{P} 450$ (CYP) isoforms is very weak $(>40 \mu \mathrm{M})$, and there is very low potential for CYP induction based on the human PXR transactivation assay. Plasma protein-binding of $\mathbf{2 3}$ was measured by equilibrium dialysis, and very low levels of plasma protein binding were observed in all species $(>10 \%$ free). Compound 23 demonstrated excellent metabolic stability in hepatocyte incubations, and the predicted clearance in all species is low, especially for human. Finally, the PK properties of compound 23 were assessed in mouse, rat, and dog following both oral and IV doses. Consistent with the predicted hepatic clearance, compound $\mathbf{2 3}$ demonstrated moderate to long halflives and very low clearance across species.

Compound $\mathbf{2 3}$ was then tested in the human prostate cancer xenograft model CWR22-BMSLD1 (Figure 3). ${ }^{15}$ Treatment with bicalutamide (2) $(150 \mathrm{mg} / \mathrm{kg}$, po, qd $\times 35$ days $)$ resulted in good tumor growth inhibition for the initial 10 days, followed by regrowth of the tumor at a rate that was similar to control. When compound 23 was dosed $(90 \mathrm{mg} / \mathrm{kg}$, po, qd $\times$ 45 days) excellent tumor growth inhibition was observed over the entire dosing period, demonstrating superior efficacy to bicalutamide (2). Additionally, we investigated the possibility of treating bicalutamide resistant tumors in this model by allowing the bicalutamide-treated tumors to triple in size followed by a switch to treatment with compound 23. As shown in Figure 3, tumor growth continued for $\sim 10$ days after switching to compound 23, followed by nearly complete tumor growth inhibition for the remainder of dosing period. We were encouraged by this result as it gave strong evidence that compound $\mathbf{2 3}$ has the potential to treat forms of prostate cancer resistant to bicalutamide (2).

Docking compound 23 into the wild-type AR ligand binding domain (Figure 4$)^{10}$ revealed the H-bond from N-705 to the 
Table 3. Summary of Androgen Receptor Biological Data and ADME Properties for Compound $23^{a}$

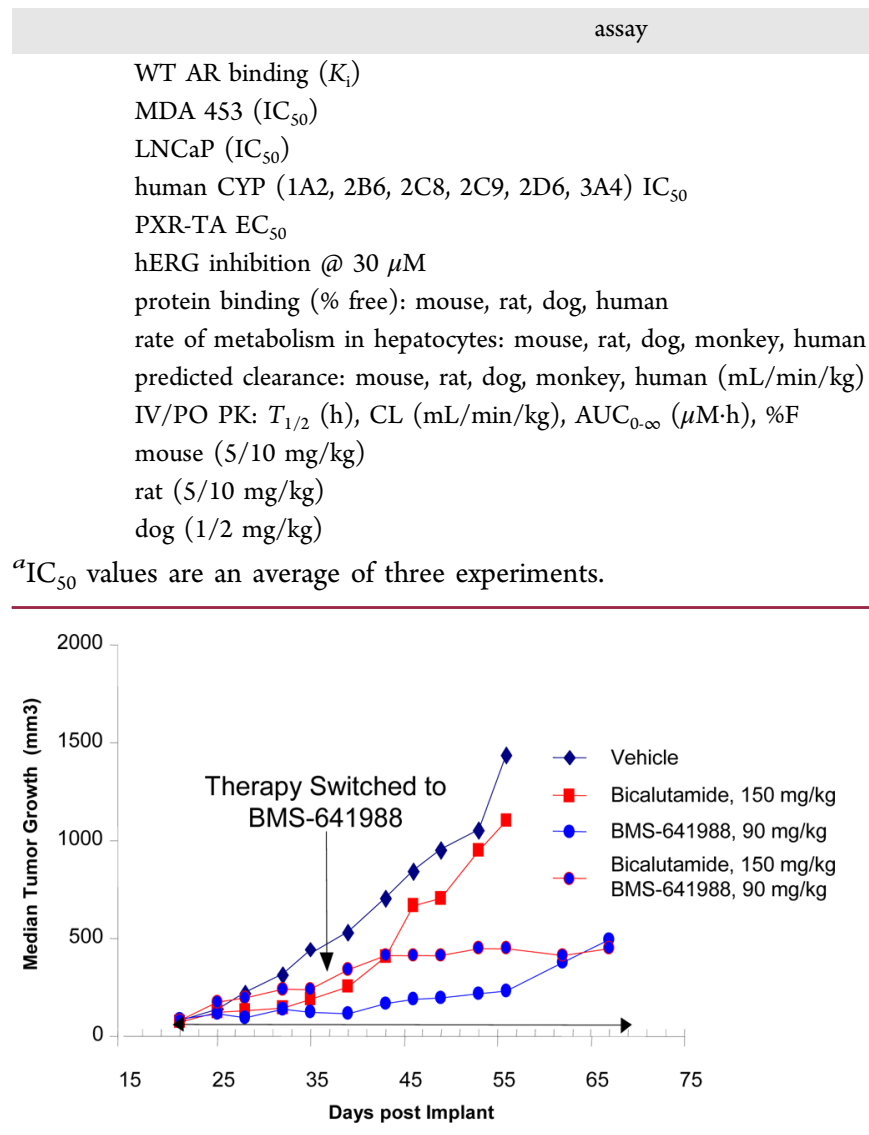

Figure 3. In vivo efficacy of compound 23 in the CWR22-BMSLD1 prostate cancer xenograft model.

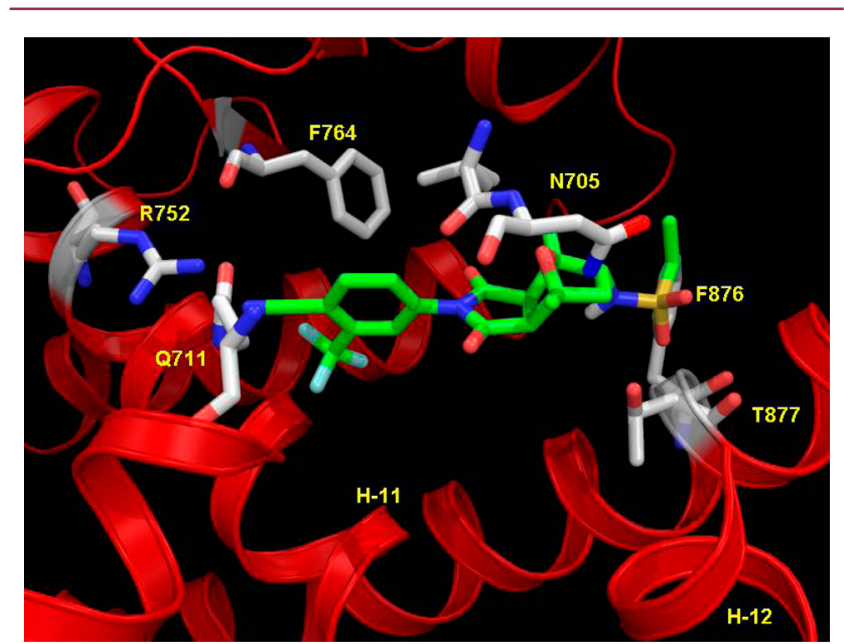

Figure 4. Compound 23 docked into a model of the WT AR ligand binding domain.

bridging oxygen is likely intact as observed for compound 5. To accommodate the endosulfonamide at C-5, F876 must reorient resulting in a positional shift of Helix-11. This significant shift of Helix-11 results in a change in the overall architecture of the LBD, potentially giving compound $\mathbf{2 3}$ the promising antagonist profile presented here.

Further profiling of compound $\mathbf{2 3}$ demonstrated an acceptable preclinical safety profile both in vitro and in vivo. This compound was selected for clinical development and advanced into phase I clinical trials. ${ }^{15,16}$

In summary, we have utilized structure-based design to identify a new series of amino [2.2.1]-oxabicyclosuccinimide AR antagonists. Lead molecules demonstrated potent antagonist activity in cellular binding and transactivation assays in vitro and had robust PK/PD profiles in the IRPW model. Compound 23 was shown to be superior to bicalutamide in the CWR22-BMSLD1 human CaP tumor xenograft model and has the potential to address acquired bicalutamide resistance based on the results from these studies.

\section{ASSOCIATED CONTENT}

S Supporting Information

Synthetic procedures and characterization data for compounds 9-23 and biological methods. The Supporting Information is available free of charge on the ACS Publications website at DOI: 10.1021 /acsmedchemlett.5b00173.

\section{AUTHOR INFORMATION}

\section{Corresponding Author}

*E-mail: aaron.balog@bms.com.

\section{Notes}

The authors declare no competing financial interest.

\section{ACKNOWLEDGMENTS}

The authors thank Linda Fleming and the Department of Discovery Synthesis at Bristol-Myers Squibb for preparation of key intermediates. We also acknowledge the Departments of Lead Discovery \& Optimization and Discovery Analytical Sciences for ADME and compound characterization support.

\section{DEDICATION}

We would like to dedicate this paper to the memory our colleague John D. DiMarco.

\section{REFERENCES}

(1) Ghafoor, A.; Jemal, A.; Thomas, H.; Murray, T.; Thun, M. Cancer statistics for African Americans. Cancer J. Clin. 2002, 52, 322325 .

(2) Crawford, E. D.; DeAntonio, E. P. Current status of combined androgen blockade: optimal therapy for advanced prostate cancer. $J$. Clin. Endocrinol. Metab. 1995, 80, 1062. 
(3) Dalesio, O. Maximum androgen blockade in advanced prostate cancer: an overview of the randomized trials. Lancet 2000, 355, 14911498.

(4) Scher, H.; Sawyers, C. Biology of progressive, castration-resistant prostate cancer: directed therapies targeting the androgen receptor signaling axis. J. Clin. Oncol. 2005, 23, 8253.

(5) Locke, J. A.; Guns, E. S.; Lubik, A. A.; Adomat, H. A.; Hendy, S. C.; Wood, C. A.; Ettinger, S. L.; Gleave, M. E.; Nelson, C. C. Androgen levels increase by intratumoral de novo steroidogenesis during progression of castration-resistant prostate cancer. Cancer Res. 2008, 68 (15), 6407-6415.

(6) Ning, Y. M.; Pierce, W.; Maher, V. E.; Karuri, S.; Tang, S. H.; Chiu, H.-J.; Palmby, T.; Zirkelback, J. F.; Marathe, D.; Mehrotra, N.; Liu, Q.; Ghosh, D.; Cottrell, C. L.; Leighton, J.; Sridhara, R.; Ibrahim, A.; Justice, R.; Pazdur, R. Enzalutamide for treatment of patients with metastatic castration-resistant prostate cancer who have previously received docetaxel; United States Food and Drug Administration approval summary. Clin. Cancer Res. 2013, 19 (22), 6067-6073.

(7) Salvati, M.; Balog, A.; Wei, D.; Pickering, D.; Attar, R.; Geng, J.; Rizzo, C.; Hunt, J.; Weinmann, R.; Martinez, R. Identification of a novel class of androgen receptor antagonists based on the bicyclic- $1 \mathrm{H}$ isoindole-1,3(2H)-dione nucleus. Bioorg. Med. Chem. Lett. 2005, 15, 389.

(8) Salvati, M.; Balog, A.; Shan, W.; Rampulla, R.; Giese, S.; Mitt, T.; Furch, J.; Vite, G.; Attar, R.; Maria, J.-K.; Geng, J.; Rizzo, C.; Gottardis, M.; Krystek, S.; Gougoutas, J.; Galella, M.; Obermeier, M.; Fura, A.; Chandrasens, G. Identification and optimization of a novel series of [2.2.1]-oxabicyclo imide-based androgen receptor antagonists. Bioorg. Med. Chem. Lett. 2008, 18, 1910-1915.

(9) Sack, J. S.; Kish, K.; Wang, C.; Attar, R.; Kiefer, S. E.; Yongmi, W.; Ginger, Y.; Scheffler, J. E.; Salvati, M. E.; Krystek, S. R.; Weinmann, R.; Einspahr, H. R. Crystallographic structures of the ligand-binding domains of the androgen receptor and its T877A mutant complexed with the natural ligand dihydrotestosterone. Proc. Natl. Acad. Sci. U. S. A. 2001, 98, 4904.

(10) Molecular modeling was performed using ICM software (Molsoft LLC, San Diego, CA). The docking of the ligands into WT AR LBD was carried out using the ICM docking procedure, which is a two step process. Initial docking of ligands was carried out using grid potential representation of the receptor and flexible ligand. Five grid potentials describe the shape, hydrophobicity, electrostatics, and hydrogen bonding potential of the receptor. The conformations from the grid were then optimized with a full atom representation of the receptor and flexible ligand, by an ICM stochastic global optimization algorithm as implemented in version 2.7 of the Molsoft ICM program. (a) Molsoft. ICM 2.7 Program Manual; Molsoft: San Diego, CA, 1998.

(b) Totrov, M.; Abagyan, R. Proteins Suppl. 1 1997, 215.

(11) Salvati, M. E.; Balog, A.; Pickering, D. A.; Giese, S.; Fura, A.; Li, W.; Patel, R.; Hanson, R. L.; Mitt, T.; Roberge, J.; Corte, J. R.; Spergel, S. H.; Rampulla, R. A.; Misra, r.; Xiao, H.-Y. Preparation of fused succinimides as modulators of nuclear hormone function. WO 20040077605.

(12) The absolute and relative stereochemistry of compound 23 was confirmed by single-crystal X-ray crystallography. The coordinates have been deposited in the Cambridge Crystallographic Data Center, \#779603.

(13) Smith, P. A. S. Curtius reaction. Org. React. 1946, 3, 337.

(14) Hershberger, L. G.; Shipley, E. G.; Meyer, R. K. Myotrophic activity of 19-nortestosterone and other steroids determined by modified levator ani muscle method. Proc. Soc. Exp. Biol. Med. 1953, 83, 175.

(15) Attar, R. M.; Kunkel, M. J.; Balog, A.; Cvijic, M. E.; Dell-John, J.; Rizzo, C. A.; Schweizer, L.; Spires, T. E.; Platero, J. S.; Obermeier, M.; Shan, W.; Salvati, M. E.; Foster, W. R.; Dinchuk, J.; Chen, S.-J.; Vite, G.; Kramer, R.; Gottardis, M. Discovery of BMS-641988, a novel and potent inhibitor of androgen receptor signaling for the treatment of prostate cancer. Cancer Res. 2009, 69, 6522-6529.

(16) Rathkopf, D.; Liu, G.; Carducci, M. A.; Eisenberger, M. A.; Anand, A.; Morris, M. J.; Slovin, S. F.; Sasaki, Y.; Takahashi, S.; Ozono,
S.; Fung, N. K. E.; Cheng, S.; Gan, J.; Gottardis, M.; Obermeier, M. T.; Reddy, J.; Zhang, S.; Vakkalagadda, B. J.; Alland, L.; Wliding, G.; Scher, H. I. Phase I dose-escalation study of the novel antiandrogen BMS-641988 in patients with castration-resistant prostate cancer. Clinc. Cancer Res. 2010, 17 (4), 880-887. 